\title{
Effect of sodium hypochlorite contamination on microhardness of dental core build-up materials
}

\author{
Florian Just WEGEHAUPT, Jasmin BETSCHART and Thomas ATTIN \\ Clinic for Preventive Dentistry, Periodontology and Cariology, University Zurich, Plattenstr. 11, Zurich 8032, Switzerland \\ Corresponding author, Florian Just WEGEHAUPT; E-mail: florian.wegehaupt@zzmk.uzh.ch
}

\begin{abstract}
This study aimed to determine the influence of sodium hypochlorite $(\mathrm{NaOCl})$ contamination on the microhardness of build-up composites. Fifty-two samples, from each of three build-up materials (LuxaCore Dual, MultiCore flow and Rebilda DC) were prepared. Half of the samples from each material were stored in physiologic saline (baseline control) while the other halves were stored in $\mathrm{NaOCl}$. After $1 \mathrm{~h}$, the samples were rinsed with tap water, cut axially and measured for Knoop hardness at different depth levels. The results were analysed by ANOVA and unpaired $t$-tests $(p<0.05)$. Significant differences in microhardness were observed for LuxaCore Dual up to $0.2 \mathrm{~mm}$, Rebilda DC up to $0.3 \mathrm{~mm}$, and for MultiCore flow up to $0.4 \mathrm{~mm}$ under the surface level. Contact with sodium hypochlorite on build-up materials causes reduction of the microhardness. The softening is not only limited on the surface, but can also be found in deeper layers of build-up materials.
\end{abstract}

Keywords: Composite, Degradation, Microhardness

\section{INTRODUCTION}

During root canal treatment, a broad range of different rinsing solutions such as chlorhexidine $(\mathrm{CHX})^{1)}$, sodium hypochlorite $(\mathrm{NaOCl})^{2)}$ or ethylenediamine tetraacetic acid (EDTA) ${ }^{3)}$ are used for dissolving necrotic pulp tissue, inactivating endotoxin, preventing the formation of a smear layer during instrumentation of the root canal or dissolving the smear layer if it has been formed $^{4}$. The most widely recommended rinsing solution is sodium hypochlorite $(\mathrm{NaOCl})$, in concentrations ranging from $0.5 \%{ }^{5}$ ) to $5.25 \%$, or even $\left.10 \%{ }^{6}\right) \mathrm{NaOCl}$ is favoured because of its high efficiency in dissolving necrotic tissues and its antimicrobial effect. Beside these positive properties of sodium hypochlorite, there are also negative side effects: dentine collagen is destroyed due to fragmentation of peptide chains ${ }^{7,8)}$, the elastic modulus and flexural strength of human dentine is, depending upon concentration, reduced ${ }^{9)}$ and the microhardness of root dentine is reduced after irrigation with $\mathrm{NaOCl}^{10)}$.

Teeth that have been degraded by caries, and in need of root canal treatment, often require a preendodontic build-up of the clinical crowns to preserve their functional integrity. The build-up also ensures aseptic principles during root canal treatment, such as facilitating rubber dam placement and coronal disinfection. As possible build-up materials, amalgam, glass ionomers or composites are commonly used in todays practice ${ }^{11)}$. Due to the known disadvantages of amalgam as build-up material, (corrosion ${ }^{12)}$ and discoloration of the remaining tooth structure) or poor mechanical properties of glass ionomers as compared with composites ${ }^{13)}$, use of composites as build-up materials should be preferred. There are different studies showing a high propensity of composite materials for alteration after contact with chemical substances such as hydrogen peroxide ${ }^{14)}$, organic acids ${ }^{15}$ or ethanol ${ }^{16)}$. After completion of the endodontic treatment, the pre-endodontic build-ups are often used as a framework for the final build-up for the prosthetic restoration of the tooth. Since the strength of the buildup $^{17)}$ is an important factor for the long-term success of the ultimate indirect restoration ${ }^{11)}$, the aim of the present study was to evaluate the influence of sodium hypochlorite treatment on the microhardness of different composite core build-up materials.

\section{MATERIALS AND METHODS}

Samples were prepared from the core build-up materials LuxaCore Dual (DMG, Hamburg, Germany) (groups 1 and 2), MultiCore flow (ivoclar vivadent, Schaan, Lichtenstein) (groups 3 and 4) and Rebilda DC (VOCO, Cuxhaven, Germany) (groups 5 and 6). For each group, 26 samples were prepared using moulds of acrylic resin (Palavit G, Kulzer, Wehrheim, Germany) with a thickness of $4 \mathrm{~mm}$ and a cylindrical hole with an inner diameter of $3 \mathrm{~mm}$. These moulds were placed on a glass plate and the holes were filled from the backside with the respective core build-up materials. After filling the holes, the samples were stored in physiologic saline for $7 \mathrm{~d}$. After this week, any excess filling material on the backside of the moulds was ground down to the level of the acrylic resin with abrasive paper (800 grit; Water Proof Silicon Carbide Paper, Streuers, Erkrat, Germany).

The samples in groups 1,3 , and 5 were stored in physiologic saline for $1 \mathrm{~h}$ and served as baseline control, while the samples of groups 2,4 , and 6 were stored in $5.25 \% \mathrm{NaOCl}$ for the same amount of time. The $\mathrm{NaOCl}$, however, was renewed every 5 minutes. After $1 \mathrm{~h}$, the moulds with the samples were removed from the water or the $\mathrm{NaOCl}$ and were rinsed with tap 
water for $5 \mathrm{~min}$. After rinsing, the moulds with the samples were cut axially to the cylindrical samples with a water-cooled diamond disc.

The microhardness of the samples were measured at depths of $0.1,0.2,0.3,0.4$, and $0.5 \mathrm{~mm}$ from the ground surface with a Knoop hardness-measuring device (High Quality Hardness Tester, Buehler, Düsseldorf, Germany). For Knoop hardness measurement a load of $10 \mathrm{~g}(\approx 0.1 \mathrm{~N})$ and an indentation time of $20 \mathrm{~s}$ was applied. At each depth level, the microhardness was measured four times and the mean hardness for this depth level was calculated.

Scanning electron microscopy pictures were taken of the build-up materials to determine if there were any visible alterations of the surfaces using a Supra 50 VP Scanning Electron Microscope (Carl Zeiss NTS, Oberkochen, Germany). Samples were sputter coated with gold before examination. SEM pictures were captured at a magnification of $1000 \times$ and an acceleration voltage of $5 \mathrm{kV}$.
With the data of a pilot study, with 8 samples in each group, a power analysis was done to determine the number of specimens required in each test group. Based on these analyses, 26 samples per group were used to gain power of $97 \%$.

Statistical analysis was performed using ANOVA followed by unpaired t-tests to detect differences in the microhardness between the samples made from the same core build-up material but treated different (group 1 vs. $2 ; 3$ vs. 4 and 5 vs. 6) on the respective depth level. The comparison was started at the depth level of $0.1 \mathrm{~mm}$ and continued to the deeper layers until the comparison revealed no significant difference between the samples stored in physiologic saline or $\mathrm{NaOCl}$. The level of significance was set at $p<0.05$.

\section{RESULTS}

The mean microhardness $( \pm \mathrm{SD})$ of the different buildup materials stored in physiologic saline or $\mathrm{NaOCl}$ is

Table 1 Table of the composition (manufacturer's information) and group allocation of the core build-up materials

\begin{tabular}{|c|c|c|}
\hline groups & material & composition \\
\hline $1+2$ & LuxaCore Dual & $\begin{array}{l}\text { Bis-GMA based matrix, barium glass and pyrog. silica, } \\
\text { Filler volume: } 72 \mathrm{wt} \%=49 \mathrm{vol} \% \\
\text { Filler size: } 0.02 \text { to } 4 \mu \mathrm{m}\end{array}$ \\
\hline $3+4$ & MultiCore flow & $\begin{array}{l}\text { Bis-GMA, urethane dimethacrylate (UDMA) and triethylene glycol } \\
\text { dimethacrylate (TEGDMA) based matrix, } \\
\text { Barium glass, ytterbiumtrifluoride, Ba-Al-fluorosilicate glass and highly } \\
\text { dispersed silicon dioxide } \\
\text { Filler volume: } 70 \mathrm{wt} \%=46 \text { vol } \% \\
\text { Filler size: } 0.04 \text { to } 25 \mu \mathrm{m}\end{array}$ \\
\hline $5+6$ & Rebilda DC & $\begin{array}{l}\text { Bis-GMA, urethane dimethacrylate (UDMA) and triethylene glycol } \\
\text { dimethacrylate (TEGDMA) based matrix, } \\
\text { benzoilperoxide, silica, bariumborosilicate glassceramic } \\
\text { Filler volume: } 71 \mathrm{wt} \%=57 \mathrm{vol} \% \\
\text { Filler size: mean } 1.5 \mu \mathrm{m}\end{array}$ \\
\hline
\end{tabular}

Table 2 Mean $( \pm \mathrm{SD})$ microhardness $[\mathrm{KHN}]$ of the different groups (core build-up materials) at different depth levels stored in different solutions. Respective groups with odd numbers were stored in physiologic saline. The $p$ values of the comparisons of the microhardness at the respective depth levels are also given

\begin{tabular}{|c|c|c|c|c|}
\hline $\begin{array}{l}\text { groups } \\
\text { (material) }\end{array}$ & depth & $\begin{array}{c}\text { stored in } \\
\text { physiologic saline }\end{array}$ & $\begin{array}{c}\text { stored in } \\
\mathrm{NaOCl}\end{array}$ & $p$-value \\
\hline \multirow{3}{*}{$\begin{array}{l}1+2 \\
\text { (LuxaCore Dual) }\end{array}$} & 0.1 & $43.554(0.399)$ & $41.530(0.399)$ & $<0.0001$ \\
\hline & 0.2 & $45.772(0.429)$ & $44.170(0.398)$ & $<0.0001$ \\
\hline & 0.3 & $46.952(0.461)$ & $46.647(0.671)$ & $>0.05$ \\
\hline \multirow{5}{*}{$\begin{array}{l}3+4 \\
\text { (MultiCore flow) }\end{array}$} & 0.1 & $44.047(0.263)$ & $41.590(0.699)$ & $<0.0001$ \\
\hline & 0.2 & $45.834(0.269)$ & $43.696(0.401)$ & $<0.0001$ \\
\hline & 0.3 & $47.093(0.326)$ & $45.737(0.295)$ & $<0.0001$ \\
\hline & 0.4 & $47.943(0.257)$ & $47.353(0.429)$ & $<0.0001$ \\
\hline & 0.5 & $48.314(0.226)$ & $48.462(0.203)$ & $>0.05$ \\
\hline \multirow{4}{*}{$\begin{array}{l}5+6 \\
\text { (Rebilda DC) }\end{array}$} & 0.1 & $44.140(0.178)$ & $42.493(0.432)$ & $<0.0001$ \\
\hline & 0.2 & $46.424(0.273)$ & $44.544(0.323)$ & $<0.0001$ \\
\hline & 0.3 & $48.025(0.236)$ & $46.783(0.484)$ & $<0.0001$ \\
\hline & 0.4 & $48.511(0.217)$ & $48.510(0.279)$ & $>0.05$ \\
\hline
\end{tabular}


given in Table 2 .

The comparison of the microhardness of groups 1 and 2 (LuxaCore Dual) at a depth level of $0.3 \mathrm{~mm}$ showed no significant difference between the samples stored in physiologic saline or $\mathrm{NaOCl}(p=0.0618)$. For the groups 3 and 4 (MultiCore flow) the comparisons of mircohardness until the depth level of $0.4 \mathrm{~mm}$ revealed significant differences between storage in physiologic saline and $\mathrm{NaOCl}$. Only the comparison at level 0.5 $\mathrm{mm}$ showed no significant difference between the microhardness of the samples stored in the different solutions $(p=0.0538)$. There was no significant difference in the microhardness of groups 5 and 6 (Rebilda DC) at a depth level exceeding $0.4 \mathrm{~mm}$ $(p=0.9890)$.

SEM pictures of all groups are given in Figure 1.

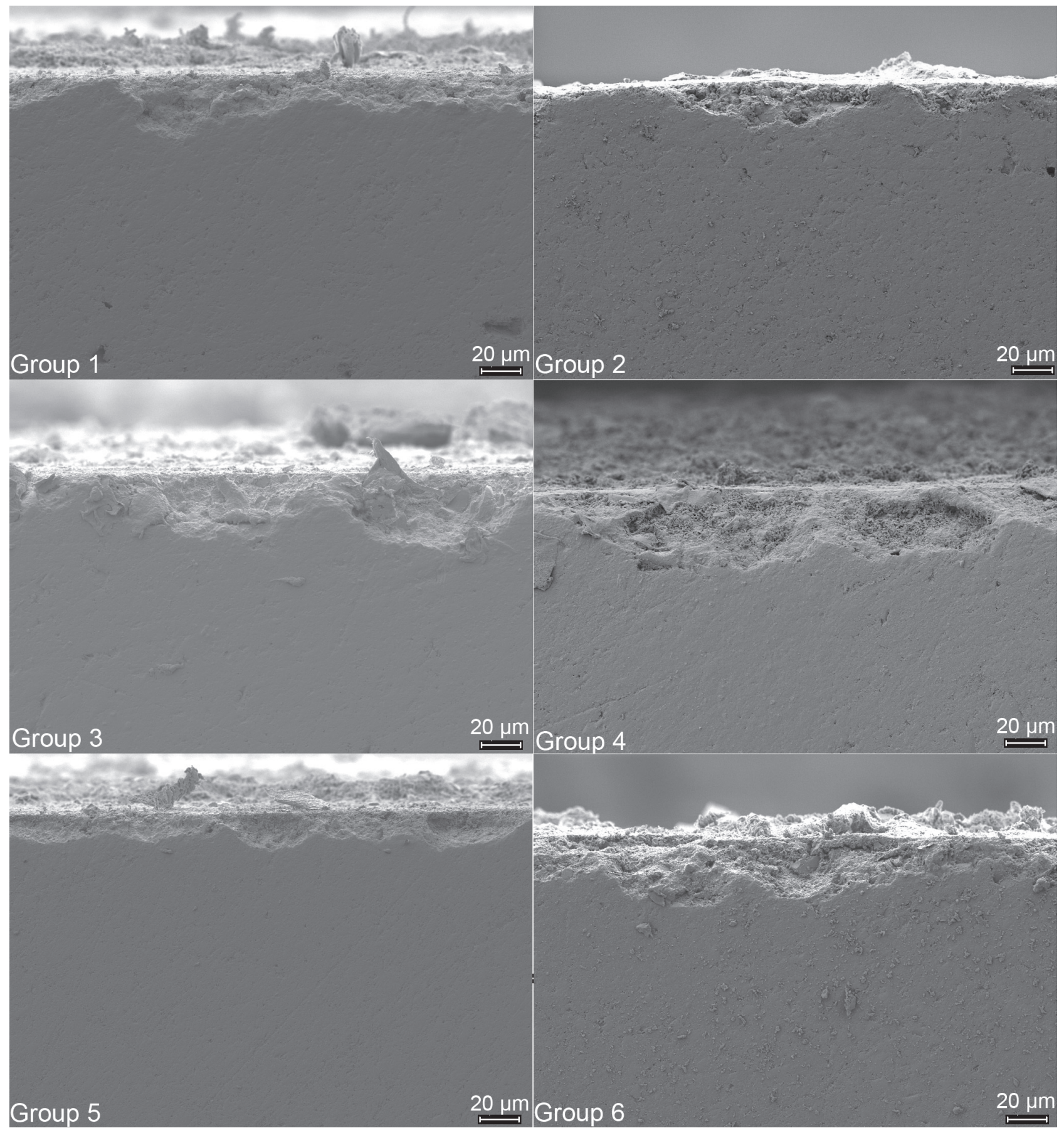

Fig. 1 SEM pictures of build-up materials samples (1+2: LuxaCore Dual, 3+4: MultiCore flow, 5+6: Rebilda DC). Groups with odd numbers were stored in physiologic saline. The samples were fixed in the SEM, so that they could be observed from the side walls, which were also used for the determination of the microhardness. 
Samples of groups 2, 4, and 6 (samples stored in $\mathrm{NaOCl}$ ) showed a more or less pronounced porous surface. No such surface phenomenon was observed for the samples in groups 1, 3, and 5 (samples stored in physiologic saline).

\section{DISCUSSION}

In the present study, alteration of composite build-up materials due to contact with sodium hypochlorite was tested by determination of Knoop microhardness at different depth levels. Various other studies have also determined alterations of composite restorative materials by measuring changes in microhardness ${ }^{14,18,19)}$. Besides measuring changes in the micohardness, other mechanical properties of resin based materials could also be tested, such as: flexural strength ${ }^{20)}$, surface roughness ${ }^{21)}$ and fracture toughness ${ }^{22)}$. The results of the present study indicate that the alterations due to $\mathrm{NaOCl}$ contact of the build-up composites are a superficial phenomenon. For testing flexural strength or other material properties usually bars of the materials are fabricated and loaded. Since the outermost layer of the materials was affected only, it is assumed that only a minimal fraction of a bar would be altered by sodium hypochlorite immersion. Thus, testing the influence of sodium hypochlorite on the flexural strength, fracture toughness or compressive stress of the materials seemed to be not appropriate. Measurements of changes in microhardness were used in this study, as this is a valid method to evaluate alterations at different depth levels of the composite materials.

In contrast to some other studies concerning alterations of composite materials ${ }^{14,23)}$, the samples were not stored in human saliva or artificial saliva during or after treatment with $\mathrm{NaOCl}$ because the present study aimed to evaluate the influence of the contact of an endodontic rinsing solution on the microhardness of build-up materials. As the use of rubber dam is indicated during root canal treatment to prevent contact of saliva with the root canal or rinsing solution with the oral cavity, no incubation in saliva was chosen to simulate the clinical situation.

This study intended to simulate the clinical situation, in which a tooth requires a build-up prior to the endodontic treatment. For this build-up, self- or dual-curing materials are widely used as they can be used in bulk application technique ${ }^{24)}$. This procedure presents a fast, economic and less technique sensitive approach. Furthermore, due to the self-curing mechanism, also in deep areas of the cavity, a sufficient hardening of the materials is ensured. In the clinical situation, an endodontic access cavity will be drilled through the build-up to reach the pulp or the root canals. On the walls of this cavity, which is located in the build-up, the $\mathrm{NaOCl}$ gets in contact with the composite. Especially in deep regions of the core buildup, an additional light curing has no additional influence on the achieved microhardness ${ }^{25,26)}$. In these areas of the build-up the dominating mechanism of curing is the self-curing mode. Due to this reason, no additional photo-irradiation has been performed in the present study.

The application time of the $\mathrm{NaOCl}$ of $1 \mathrm{~h}$ was chosen to simulate the clinical situation during a complete endodontic treatment starting from the trepanation up to the obturation of the root canal with multiple rinsing with fresh $\mathrm{NaOCl}$ as it is commonly done during the endodontic treatment. A study ${ }^{27}$ reported an irrigation time with $\mathrm{NaOCl}$ between 15 min and $1 \mathrm{~h}$ being necessary to have bactericidal effects against $F$. nucleatum and $S$. intermedius. A recent study by Retamozo et al. $(2010)^{28)}$ reported an irrigation time of $40 \mathrm{~min}$ minimum for effective removing of $E$. faecalis from infected dentine. Furthermore, an incubation time of 1 hour or even longer has been used in different other studies ${ }^{9,29,30)}$ concerning the effect of $\mathrm{NaOCl}$ irrigation on dentine micromechanical properties.

Other studies have shown an influence of sodium hypochlorite treatment on the microhardness of dentine $^{10,31)}$. In the present study, the findings were similar for composite materials. Furthermore, the influence of sodium hypochlorite on the microhardness of composite build-up materials was confirmed not only for the surface but also for deeper layers of the restorative materials. Compared with the findings of Hannig et al. (2007) ${ }^{14)}$, where softening of light-curing composites after contact with bleaching agents was observed even in $1 \mathrm{~mm}$ depth, the softening observed in the present study seems to be a more superficial phenomenon.

Sodium hypochlorite, especially in $5.25 \%$ concentration, is known as a strong bleaching agent ${ }^{4)}$. Like other bleaching agents, its reactive chlorine forms (hypochlorite and hypochlorous acid) show high oxidizing potential ${ }^{32}$. As discussed elsewhere, substrates with oxidative capacities might cleave polymer chains, which results in a decomposing of the resin based materials ${ }^{14)}$. It might be assumed that this degradation leads to a softening and reduction of the microhardness of the so affected composite materials. Another possible consideration how oxidative substrates might influence the hardness of composites is that they cause a filler matrix debonding ${ }^{32}$. These explanations provide possible reasons for the different outcomes for the different build-up composites used in the present study. When comparing the information given by the manufactures concerning the composition of the resin matrix of MultiCore flow and Rebilda DC, it seems that there is no qualitative difference but there might be a quantitative one. There seems to be a high discrepancy in the filler volume of both materials. Taking into consideration, that a higher percentage filler volume results in a lower percentage matrix volume, the difference in the findings of the present study for these materials might be explained with the different amount of matrix resin to be decomposed while in contact with the $\mathrm{NaOCl}$. 
Vol\% of filler of LuxaCore Dual and MultiCore flow is comparable, but the results of the present study for these materials are different. The lowest softening was observed for LuxaCore Dual while MultiCore flow showed softening in even double of the depth compared with LuxaCore Dual. This might be attributed to the difference in the composition of the resin matrix of both materials. LuxaCore Dual has a resin matrix solely of Bis-GMA, while the resin matrix of MultiCore flow is composed of Bis-GMA, urethane dimethacrylate (UDMA) and triethylene glycol dimethacrylate (TEGDMA). Polymerisation of Bis GMA results in the formation of hydrogen bonds between $\mathrm{OH}$ - and estergroups while the polymerisation of UDMA results in bindings between NH-groups ${ }^{33)}$. As the strength of hydrogen bonds between $\mathrm{OH}$ - and ester-groups is stronger than that of $\mathrm{NH}$ groups $^{33)}$, it might be concluded, that the bond between NH groups is more susceptible to decomposition during chemical attacks like it occurs during contact with $\mathrm{NaOCl}$. This might explain the higher susceptibility due to softening in the present study of MultiCore flow (Bis-GMA; UDMA; TEGDMA) compared with LuxaCore Dual (Bis-GMA only). Furthermore, this might also explain the difference in the findings for LuxaCore Dual and Rebild DC (Bis-GMA, UDMA; TEGDMA).

\section{CONCLUSION}

The results of the present study show that contact with sodium hypochlorite on composite build-up materials causes a softening of the build-up materials. This softening is limited to the outermost layer of the materials. Alteration of the composite due to the contact with $\mathrm{NaOCl}$ seems not to require a complete replacement of the build-up prior to the definitive prosthetic restoration.

\section{REFERENCES}

1) Zamany A, Safavi K, Spangberg LS. The effect of chlorhexidine as an endodontic disinfectant. Oral Surg Oral Med Oral Pathol Oral Radiol Endod 2003; 96: 578-581.

2) Naenni N, Thoma K, Zehnder M. Soft tissue dissolution capacity of currently used and potential endodontic irrigants. J Endod 2004; 30: 785-787.

3) Lester KS, Boyde A. Scanning electron microscopy of instrumented, irrigated and filled root canals. Br Dent $\mathrm{J}$ 1977; 143: 359-367.

4) Zehnder M. Root canal irrigants. J Endod 2006; 32: 389398.

5) Dakin HD. On the use of certain antiseptic substances in treatment of infected wounds. Br Med J 1915; 2: 318-320.

6) Matsumoto T, Nagai T, Ida K, Ito M, Kawai Y, Horiba N, Sato R, Nakamura H. Factors affecting successful prognosis of root canal treatment. J Endod 1987; 13: 239-242.

7) Stoward PJ. A histochemical study of the apparent deamination of proteins by sodium hypochlorite. Histochemistry 1975; 45: 213-226.

8) Torres CR, de Araujo MA, Torres AC. Effects of dentin collagen removal on microleakage of bonded restorations. $J$ Adhes Dent 2004; 6: 33-42.

9) Marending M, Luder HU, Brunner TJ, Knecht S, Stark WJ,
Zehnder M. Effect of sodium hypochlorite on human root dentine--mechanical, chemical and structural evaluation. Int Endod J 2007; 40: 786-793.

10) Slutzky-Goldberg I, Maree M, Liberman R, Heling I. Effect of sodium hypochlorite on dentin microhardness. J Endod 2004; 30: 880-882.

11) Stober T, Rammelsberg P. The failure rate of adhesively retained composite core build-ups in comparison with metaladded glass ionomer core build-ups. J Dent 2005; 33: 27-32.

12) Dewald JP, Arcoria CJ, Marker VA. Evaluation of the interactions between amalgam, cement and gold castings. $J$ Dent 1992; 20: 121-127.

13) Bonilla ED, Mardirossian G, Caputo AA. Fracture toughness of various core build-up materials. J Prosthodont 2000; 9: 14-18.

14) Hannig C, Duong S, Becker K, Brunner E, Kahler E, Attin T. Effect of bleaching on subsurface micro-hardness of composite and a polyacid modified composite. Dent Mater 2007; 23: 198-203.

15) Asmussen E. Softening of BISGMA-based polymers by ethanol and by organic acids of plaque. Scand J Dent Res 1984; 92: 257-261.

16) Sarrett DC, Coletti DP, Peluso AR. The effects of alcoholic beverages on composite wear. Dent Mater 2000; 16: 62-67.

17) Cohen BI, Pagnillo MK, Newman I, Musikant BL, Deutsch AS. Retention of a core material supported by three post head designs. J Prosthet Dent 2000; 83: 624-628.

18) Mayworm CD, Camargo SSJ, Bastian FL. Influence of artificial saliva on abrasive wear and microhardness of dental composites filled with nanoparticles. J Dent 2008; 36: 703-710.

19) Jung YH, Park JK, Hyun SH, Seol HJ, Kim HI, Kwon YH. Effect of acetic $\mathrm{NaF}$ solutions on fluoride-containing dental restorative materials. Dent Mater J 2007; 26: 68-77.

20) Catelan A, Padilha AC, Salzedas LM, Coclete GA, dos Santos PH. Effect of radiotherapy on the radiopacity and flexural strength of a composite resin. Acta Odontol Latinoam 2008; 21: 159-162.

21) de Moraes RR, Marimon JL, Schneider LF, Sinhoreti MA, Correr-Sobrinho L, Bueno M. Effects of 6 months of aging in water on hardness and surface roughness of two microhybrid dental composites. J Prosthodont 2008; 17: 323-326.

22) Ferracane JL, Hopkin JK, Condon JR. Properties of heattreated composites after aging in water. Dent Mater 1995; 11: 354-358.

23) Schemehorn B, Gonzalez-Cabezas C, Joiner A. A SEM evaluation of a $6 \%$ hydrogen peroxide tooth whitening gel on dental materials in vitro. J Dent 2004; 32 Suppl 1: 35-39.

24) Bolhuis PB, de Gee AJ, Kleverlaan CJ, El Zohairy AA, Feilzer AJ. Contraction stress and bond strength to dentin for compatible and incompatible combinations of bonding systems and chemical and light-cured core build-up resin composites. Dent Mater 2006; 22: 223-233.

25) Sigemori RM, Reis AF, Giannini M, Paulillo LA. Curing depth of a resin-modified glass ionomer and two resin-based luting agents. Oper Dent 2005; 30: 185-189.

26) Blackman R, Barghi N, Duke E. Influence of ceramic thickness on the polymerization of light-cured resin cement. J Prosthet Dent 1990; 63: 295-300.

27) Spratt DA, Pratten J, Wilson M, Gulabivala K. An in vitro evaluation of the antimicrobial efficacy of irrigants on biofilms of root canal isolates. Int Endod J 2001; 34: 300307.

28) Retamozo B, Shabahang S, Johnson N, Aprecio RM, Torabinejad M. Minimum Contact Time and Concentration of Sodium Hypochlorite Required to Eliminate Enterococcus faecalis. J Endod 2010; 36: 520-523.

29) Grigoratos D, Knowles J, Ng YL, Gulabivala K. Effect of exposing dentine to sodium hypochlorite and calcium 
hydroxide on its flexural strength and elastic modulus. Int Endod J 2001; 34: 113-119.

30) Sobhani OE, Gulabivala K, Knowles JC, Ng YL. The effect of irrigation time, root morphology and dentine thickness on tooth surface strain when using 5\% sodium hypochlorite and 17\% EDTA. Int Endod J 2010; 43: 190-199.

31) Oliveira LD, Carvalho CA, Nunes W, Valera MC, Camargo $\mathrm{CH}$, Jorge AO. Effects of chlorhexidine and sodium hypochlorite on the microhardness of root canal dentin. Oral
Surg Oral Med Oral Pathol Oral Radiol Endod 2007; 104: e125-128.

32) Wattanapayungkul P, Yap AU. Effects of in-office bleaching products on surface finish of tooth-colored restorations. Oper Dent 2003; 28: 15-19.

33) Barszczewska-Rybarek IM. Structure-property relationships in dimethacrylate networks based on Bis-GMA, UDMA and TEGDMA. Dent Mater 2009; 25: 1082-1089. 